\title{
FFQ versus repeated 24-h recalls for estimating diet-related environmental impact
}

Elly Mertens ${ }^{1 *}$, Anneleen Kuijsten ${ }^{1,2}$, Johanna M. Geleijnse ${ }^{1,2}$, Hendriek C. Boshuizen ${ }^{1,3}$, Edith J. M. Feskens ${ }^{1}$ and Pieter van't Veer ${ }^{1,2}$

\begin{abstract}
Background: There is an increasing interest in estimating environmental impact of individuals' diets by using individual-level food consumption data. However, like assessment of nutrient intakes, these data are prone to substantial measurement errors dependent on the method of dietary assessment, and this often result in attenuation of associations.
\end{abstract}

Purpose: To investigate the performance of a food frequency questionnaire (FFQ) for estimating the environmental impact of the diet as compared to independent 24-h recalls (24hR), and to study the association between environmental impact and dietary quality for the FFQ and 24hR.

Methods: We analysed cross-sectional data from 1169 men and women, aged 20-76 years, who participated in the NQplus study, the Netherlands. They completed a 216-item FFQ and two replicates of web-based 24hR. Life cycle assessments of 207 food products were used to calculate greenhouse gas emissions, fossil energy and land use, summarised into an aggregated score, pReCiPe. Validity of the FFQ was evaluated against 24hRs using correlation coefficients and attenuation coefficients. Associations with dietary quality were based on Dutch Healthy Diet 15index (DHD15-index) and Nutrient Rich Diet score (NRD9.3).

Results: For pReCiPe, correlation coefficient between FFQ and 24hR was 0.33 when adjusted for covariates age, gender and BMl, and increased to 0.76 when de-attenuated for within-subject variation in the $24 \mathrm{hR}$. Energyadjustment slightly reduced these correlations ( $r=0.71$ for residuals of observed values and 0.59 for residuals of density values). Covariate-adjusted attenuation coefficient for the FFQ was $0.56\left(\kappa_{1}=0.56\right.$ and $\Lambda_{1}=0.65$ for observed and density residuals), slightly lower than without covariate adjustment. Diet-related environmental impact was inversely associated with the food-based DHD15-index for both FFQ and 24hR, while associations with the nutrientbased NRD9.3 were inconsistent.

Conclusions: The FFQ slightly underestimated environmental impact when compared to 24hR. Associations with dietary quality are highly dependent on the diet score used, and less dependent on the method of dietary assessment.

\footnotetext{
* Correspondence: elly.mertens@wur.nl

${ }^{1}$ Division of Human Nutrition and Health, Wageningen University, PO Box

8129, 6700, EV, Wageningen, The Netherlands

Full list of author information is available at the end of the article
}

(c) The Author(s). 2019 Open Access This article is distributed under the terms of the Creative Commons Attribution 4.0 International License (http://creativecommons.org/licenses/by/4.0/), which permits unrestricted use, distribution, and reproduction in any medium, provided you give appropriate credit to the original author(s) and the source, provide a link to the Creative Commons license, and indicate if changes were made. The Creative Commons Public Domain Dedication waiver (http://creativecommons.org/publicdomain/zero/1.0/) applies to the data made available in this article, unless otherwise stated. 


\section{Background}

Climate change has led to an increased interest in shifting towards environmentally-friendly food consumption patterns. Several studies have estimated the environmental impact related to dietary intake $[1,2]$. This, however, is very challenging due to e.g.: high diversity in food products, their production practices, as well as inconsistencies in life cycle assessment (LCA) methods, including data availability and quality [3, 4]. On top of these, assessment of diet-related environmental impact depends on the method of dietary assessment, ranging from per capita food availability at the national level to food consumption at the individual level [5].

Assessment of the diet-related environmental impact was initially studied in the production domain dealing with a limited number of primary agricultural commodities of basic food items, using data on food availability, i.e. apparent food consumption data, defined as production exports + imports, sourced from Eurostat and FAO databases. With the increasing availability of LCA data on single food products, it is now possible to study diet-related environmental impact in the consumer domain using food consumption data collected at the individual level. Moreover, individual-level dietary assessment allows combining environmental impact of the diet with other diet-related aspects, like dietary quality, acceptability of the diet, etc. [6]. So far, the few studies that have addressed this association with dietary quality used a multiple-day diet record [7-10] or a food frequency questionnaire (FFQ) [11, 12], but produced no clear results. Studies using diet records most often found that diet-related environmental impact was not associated with dietary quality [7-10], while an inverse association was reported in studies using FFQ [11, 12]. However, evaluation studies have shown that FFQs are subject to large between-person errors and introduce attenuation in associations with nutritional health outcomes $[13,14]$. Moreover, as compared to $24 \mathrm{hRs}$, FFQs are likely to perform less well for environmental impact as they purposively aggregate and incorporate food items that differentiate diets with respect to dietary quality rather than environmental impact. Until now, little is known about the potential influence of the method of dietary assessment on properly estimating diet-related environmental impact and its association with dietary quality.

Literature has acknowledged that all reported dietary intake values are prone to substantial measurement errors, both systematic, including intake-related and person-specific bias, and random errors, that often results in attenuation of the association [15]. In order to correct associations for dietary measurement error, a regression calibration approach, as introduced by Rosner et al. [16], is commonly used, which calculates attenuation coefficients in order to adjust for the bias caused by measurement error. Correct application of the regression calibration, however, is not guaranteed without a reference instrument that is unbiased and has errors independent of true exposure and independent of errors in dietary-reports [15, 17].

In the present study, we first evaluated the FFQ as a method to estimate environmental impact of individuals' diets as compared to the $24 \mathrm{hR}$ as the individual-level and detailed reference method of dietary assessment. Second, we studied the association between food-based and nutrient-based diet scores based on $24 \mathrm{hR}$ and environmental impact based on either $24 \mathrm{hR}$ or FFQ with adjustment for random and systematic errors in assessment.

\section{Methods}

\section{Study population}

The present study was conducted with data obtained from the Nutrition Questionnaires plus (NQplus) study, conducted in Wageningen and its surroundings, the Netherlands [18, 19]. Initially, 2048 men and women, aged 20-70 years were recruited between 2011 and 2013. Subjects filled out an FFQ, general and health questionnaires, and underwent physical examinations at baseline, and multiple web-based recalls $24 \mathrm{hRs}$ were administered. Frequency of sampling $24 \mathrm{hRs}$ was not identical for each subject. Recall days were randomly selected and scheduled across the first year of the study with at least 40 days in between each other. Of the NQplus study population, a total of 1653 subjects completed one FFQ at a baseline and a total of 1430 subjects completed two replicates of a web-based $24 \mathrm{hR}$ spaced over one-to-five month period. We excluded 185 subjects with misreporting for the FFQ, and 37 subjects with misreporting for the $24 \mathrm{hR}$. A total of 1169 subjects completed both an FFQ and two replicates of the 24hR, and remained for analysis (Fig. 1). The NQplus study was approved by the ethics committee of Wageningen University and conducted according to the Declaration of Helsinki, and all subjects provided their written informed consent.

\section{Methods of dietary assessment}

The 24hR was a self-administered web-based highly-standardised version using the five-step multiple pass method, a validated technique to increase the accuracy of recalls [20]. Recall dates were randomly selected and scheduled evenly across the year and days of the week. For each subject, we included two recalls spaced over a one to five months period, resulting in 2338 recalls. Daily energy and nutrient intakes were calculated by multiplying the intake of food items with their nutrient content using the Dutch food composition table of 2011 [21]. 


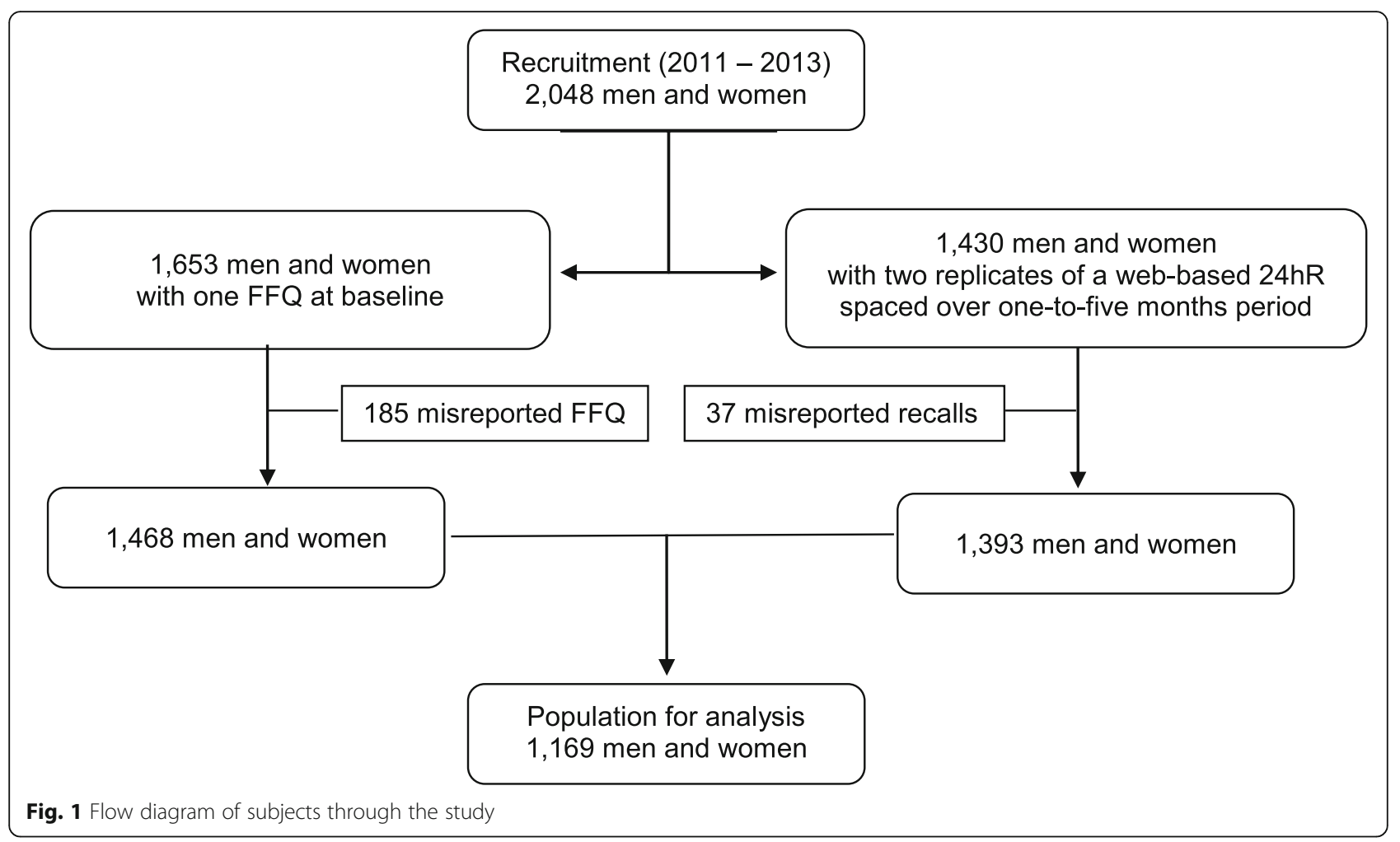

The FFQ was developed to assess habitual intake, and consisted of 216 food items with questions on frequency and consumed amounts with a one-month reference period. This self-administered semi-quantitative FFQ was validated for energy intake [22], macronutrients, dietary fibre and selected micronutrients [23].

\section{Estimating diet-related environmental impact}

Environmental impact was calculated based on LCA data from Blonk Consultants, available for 207 food products commonly consumed in the Dutch diet (Blonk Consultants data set version 2016) [24]. LCA were from cradle to grave, and included production, processing, packaging, transport, storage, preparation, cooking, avoidable waste and unavoidable food waste (inedible parts) at home, and waste incineration. Greenhouse gas emission (GHGE; in kilogram $\mathrm{CO}_{2}$-equivalents ( $\mathrm{kg}$ $\left.\mathrm{CO}_{2} \mathrm{e}\right) /$ day) covers carbon dioxide $\left(\mathrm{CO}_{2}\right)$ emissions through the use of fossil fuels, methane $\left(\mathrm{CH}_{4}\right)$ released during rearing of cattle and cultivation of certain crops, and nitrous oxide $\left(\mathrm{N}_{2} \mathrm{O}\right)$ released from fertilizers, manure and ploughing of grassland. Fossil energy use (FE, in Mega Joules (MJ)/day) covers the resources containing hydrocarbons needed for the production of food, and land use (LU, in $\mathrm{m}^{2 *}$ year/day) the surface needed for the production of food during a certain period of time. Environmental impact of the diet was reported for each impact category individually (i.e. GHGE, FE and LU), and aggregated - weighing their relative importance into a single measure of environmental impacts, i.e. pReCiPe based on the principles of the ReCiPe method [25], calculated as

$$
p R e C i P e=0.0459 * G H G E+0.0025 * F E+0.0439 * L U
$$

where GHGE is greenhouse gas emissions in kilogram $\mathrm{CO}_{2}$ equivalents, $\mathrm{FE}$ fossil energy use in mega joules, $\mathrm{LU}$ land use in $\mathrm{m}^{2 *}$ year, and weighing values were obtained using a panel approach, then characterised and normalised using the year 2000 as reference year, and information was gathered for the European situation, as specified by the authors.

These LCA data were linked to food consumption data of the $24 \mathrm{hRs}$ and FFQ to calculate individual daily diet-related environmental impact using coding of the Dutch food composition table. For the 24hR, of the 1264 food products consumed in this cohort, 1198 (95\%) food products were linked to LCA data either by direct matching or extrapolation. There was a direct match on food code for 203 (16\%) food products consumed in this cohort, which covered $50 \%$ of total food weight intake, excluding beverages, and 53\% of total energy intake. Extrapolations were made to other food products consumed according to the $24 \mathrm{hR}$ based on similarities in type of food product (11\%) or production method (56\%), and based on ingredient composition by using standard 
recipes for composite foods (12\%). For the FFQ, the 216 FFQ-items were disaggregated into 1159 food products with different contribution percentages based on Dutch dietary survey data, coded by the Dutch food composition table, and subsequently matched with LCA data on their food code. When LCA data were not available for all food products within an FFQ-item $(n=135)$, we scaled the food products with LCA data in such a way that the FFQ-item was $100 \%$ represented by those food products, while accounting for their contribution percentage. LCA data were available for 167 FFQ-items covering $89 \%$ of the total food weight and $86 \%$ of the total energy intake. Remaining FFQ-items $(n=49)$ received an extrapolated value based on similarities in type of food product, production method and ingredient composition.

\section{Estimating dietary quality}

Dietary estimates of the $24 \mathrm{hR}$ were analysed for their dietary quality using a diet score based on food groups, i.e. the Dutch Healthy Diet Index 2015 (DHD15-index) [26], and one based on nutrients, i.e. the Nutrient Rich Diet score (NRD9.3) [10, 27]. DHD15-index consists of fifteen food groups included the Dutch food-based dietary guidelines of 2015: vegetables, fruit, wholegrain products, legumes, nuts, dairy, fish, tea, fats and oils, filtered coffee, red meat, processed meat, sweetened beverages and fruit juices, alcohol, and salt. A proportional score between 0 and 10 was assigned to all other food groups, and the final score was the mean of all food groups and ranged from 0 (minimal adherence) to 10 (maximal adherence). NRD9.3 was based on the principles of the Nutrient Rich Food Index, NRF9.3 $[28,29]$. This NRF9.3 algorithm is the unweighted sum of percentage daily values (DVs) for nine nutrients to encourage (protein, dietary fibre, calcium, iron, potassium, magnesium, and vitamin $\mathrm{A}, \mathrm{C}$ and $\mathrm{E}$ ) minus the sum of percentage maximum recommended values for three nutrients to limit (saturated fat, added sugar, and sodium), calculated per $100 \mathrm{kcal}$ and capped at $100 \% \mathrm{DV}$. We expressed nutrient intakes relative to a daily energy intake of $2500 \mathrm{kcal}$ for men and of $2000 \mathrm{kcal}$ for women to obtain a daily nutrient density score.

\section{Covariates}

Data were collected on age (years), sex, educational level (low: no, lower or lower vocational education; intermediate: intermediate vocational; and high: higher vocational or university), smoking status (never/former/current) by means of questionnaires. Physical activity was assessed using the Short QUestionnaire to Asses Health enhancing physical activity (SQUASH) [30], and was categorised according to the average time spent per week doing commuting, leisure-time and household activities, and activities at work (Metabolic Equivalent of Task
(MET) in minutes per week); low: <500; moderate: $500 \leq \mathrm{MET}<1000$; high: MET 21000 ). Body weight was measured by a trained research assistant without shoes and heavy clothing and with empty pockets on a digital scale (SECA 877; SECA Corp.), and height was measured without shoes using a stadiometer (SECA 213; SECA Corp.). Body Mass Index (BMI) was calculated as body weight $(\mathrm{kg})$ divided by height squared $\left(\mathrm{m}^{2}\right)$.

\section{Measurement error model}

It was assumed that estimates obtained from $24 \mathrm{hRs}$ were the best available standards to approximate true diet-related environmental impact, as no independent reference methods are available [31, 32]. In contrast, in the FFQ, constant bias at the group level, intake-related bias and person-specific bias were assumed to be present. The measurement error model was specified as:

$$
\begin{array}{cc}
\text { 24-hour recall }(R): & R=T+e_{R} \\
\operatorname{FFQ}(Q): & Q=A_{Q}+B_{Q} T+q+e_{Q}
\end{array}
$$

where $\mathrm{T}$ is the true (unknown) intake, e the withinperson random error, and $\mathrm{A}$ the overall constant bias at group level, B the intake-related bias and $\mathrm{q}$ the personspecific bias for the FFQ. By this model, it was assumed that estimates from two replicates of the $24 \mathrm{hRs}$ are statistically independent and contains no intake-related bias and no person-specific bias [33].

\section{Statistical methods}

To evaluate the performance of the FFQ versus the $24 \mathrm{hR}$, linear mixed models with a random intercept for subjects were applied to account for the two replicates of the $24 \mathrm{hRs}$ per subject. Attenuation coefficient was estimated as the slope in the linear regression of the reference method (i.e. 24hR) on the FFQ through the following linear mixed model:

$$
R_{i j}=\lambda_{0}+\lambda_{1} Q_{i}+\mu_{i}+e_{i j}
$$

where $R_{i j}$ is the $j^{\text {th }}$ observation of the recall for the $i^{\text {th }}$ individual, $Q_{i}$ the FFQ-report of that individual, $u_{j}$ the random intercept for that individual and $e_{i j}$ the random within-person variation, $\lambda_{0}$ is the method-specific intercept and $\lambda_{1}$ the attenuation coefficient. The random terms were assumed to be independent, normally distributed with mean zero and variances $\sigma^{2}(\mathrm{u})$ and $\sigma^{2}(\mathrm{e})$. Correlation coefficients between FFQ and the average of two 24hRs were estimated as Pearson correlations, without and with adjustment for covariates age, gender and BMI. To account for within-subject variation in the $24 \mathrm{hR}$, correlation coefficients were de-attenuated by dividing by the square root of the intra-class correlation coefficient (ICC) of the replicates of the 24hR; ICC was calculated as the variance in random intercept divided 
by the total variance obtained from a mixed model without $\mathrm{Q}$ as covariate under the assumption of no personspecific bias [34].

In the analysis of diet associations, e.g.: impact vs quality, covariate adjustment is essential for the internal study validity, hence the usual covariates age (continuous), gender (men/women), and BMI (continuous) were included in the calibration equation [31]. In addition, stratified analyses were performed for men and women separately (results in Additional files 1 and 2). Specific attention was paid to energy intake as a key covariate in diet analyses, using linear regression of diet-related environmental impact on energy-intake [35]; the latter was done for both observed values and densities, i.e. observed values divided by total energy intake, and standardised to $2000 \mathrm{kcal}$. Densities and residuals were calculated for each method of dietary assessment using estimates as measured by that method of dietary assessment.

To illustrate the possible influence of the method of dietary assessment, we analysed the association between dietary quality and diet-related environmental impact by linear regression analyses with adjustments for age, gender, BMI, and energy intake. Dietary quality was assessed by the food-based DHD15-index and the nutrient-based NRD9.3 both based on the $24 \mathrm{hR}$ as the alleged gold standard reference. When the (explanatory) diet-related environmental impact variables were derived from the $24 \mathrm{hR}$ the associations with diet scores were corrected for within-subject variation using Best Linear Unbiased Predictions (BLUPs) from a mixed model without $\mathrm{Q}$ as covariate [36]. When the diet-related environmental impact variables were based on the FFQ, the association with dietary quality was calibrated using a mixed model accounting for random effects (i.e. the predicted values from eq. 2 with covariates added). All statistical analyses were performed using SAS version 9.3 (SAS Institute, Inc.).

\section{Results}

Mean age of the population was 53 (SD 12) years and mean BMI was 25.6 (SD 3.7) $\mathrm{kg} / \mathrm{m}^{2}$ (Table 1). More than $60 \%$ of the population completed a level of higher education, less than $35 \%$ had a high level of physical activity and less than $10 \%$ was current smoker. Approximately

Table 1 General characteristics of the NQplus study $(n=1169)^{a}$

\begin{tabular}{|c|c|c|c|c|c|c|}
\hline \multirow[b]{2}{*}{ Age, years } & \multicolumn{2}{|c|}{ Total $(n=1169)$} & \multicolumn{2}{|c|}{ Men $(n=606)$} & \multicolumn{2}{|c|}{ Women $(n=563)$} \\
\hline & 53.2 & $(11.5)$ & 55.6 & $(10.7)$ & 50.6 & $(11.7)$ \\
\hline $\mathrm{BMl}, \mathrm{kg} / \mathrm{m}^{2} \mathrm{~b}$ & 25.6 & (3.7) & 26.2 & (3.3) & 24.9 & (3.9) \\
\hline \multicolumn{7}{|l|}{ Education level $^{c}$} \\
\hline Low & 67 & $(6 \%)$ & 46 & $(7 \%)$ & 21 & $(4 \%)$ \\
\hline Intermediate & 343 & $(29 \%)$ & 162 & $(27 \%)$ & 181 & $(32 \%)$ \\
\hline High & 757 & $(65 \%)$ & 397 & $(66 \%)$ & 360 & $(64 \%)$ \\
\hline \multicolumn{7}{|l|}{ Physical activity } \\
\hline Low & 539 & $(46 \%)$ & 249 & $(41 \%)$ & 290 & (51\%) \\
\hline Moderate & 224 & $(19 \%)$ & 114 & $(19 \%)$ & 110 & (20\%) \\
\hline High & 406 & $(35 \%)$ & 243 & $(40 \%)$ & 163 & (29\%) \\
\hline \multicolumn{7}{|l|}{ Smoking status ${ }^{d}$} \\
\hline Never & 587 & $(53 \%)$ & 263 & $(45 \%)$ & 324 & $(61 \%)$ \\
\hline Former & 435 & (39\%) & 259 & $(45 \%)$ & 176 & $(33 \%)$ \\
\hline Current & 90 & $(8 \%)$ & 56 & $(10 \%)$ & 34 & $(6 \%)$ \\
\hline Energy intake, $\mathrm{kcal} / \mathrm{d}^{\mathrm{e}}$ & 2012 & (583) & 2200 & $(617)$ & 1808 & $(466)$ \\
\hline DHD15-index ${ }^{e}$ & 4.92 & $(1.00)$ & 4.61 & $(0.94)$ & 5.29 & $(0.96)$ \\
\hline NRD9. $3^{\mathrm{e}}$ & 500 & $(72)$ & 493 & (71) & 507 & (73) \\
\hline GHGE, $\mathrm{kgCO}_{2} \mathrm{e} / \mathrm{d}^{\mathrm{e}}$ & 3.64 & $(1.46)$ & 3.94 & $(1.60)$ & 3.32 & $(1.20)$ \\
\hline $\mathrm{FE}, \mathrm{MJ} / \mathrm{d}^{\mathrm{e}}$ & 31.10 & $(9.20)$ & 33.36 & $(9.83)$ & 28.66 & (7.77) \\
\hline$L U, m^{2 *}$ year/d ${ }^{e}$ & 4.15 & $(1.82)$ & 4.57 & $(1.99)$ & 3.71 & $(1.51)$ \\
\hline pReCiPe ${ }^{e}$ & 0.43 & $(0.16)$ & 0.46 & $(0.18)$ & 0.39 & $(0.14)$ \\
\hline
\end{tabular}

Abbreviations: DHD15-index, Dutch Healthy Diet Index 15; NRD9.3, Nutrient Rich Diet score 9.3;GHGE, greenhouse gas emissions; FE, fossil energy use; LU, land use; pReCiPe, a weighted summary score for GHGE, FE, and LU

a Values are expressed as mean (standard deviations), numbers and percentages. Comparisons between men and women were tested by independent samples $t-$ test for continuous variables and chi-square test for categorical variables. All characteristics above were statistically significant using $P$-value below 0.05 . ${ }^{b}$ Data were available for 1168 subjects, i.e. 605 men and 563 women. ${ }^{\mathrm{C} D a t a}$ were available for 1167 subjects, i.e. 605 men and 562 women. ${ }^{\mathrm{d} D a t a}$ were available for 1112

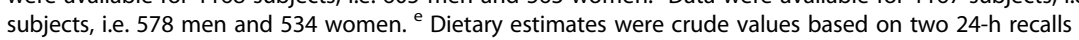


half of the population (48\%) were women, who were on average younger, had a lower BMI, a lower level of physical activity, and a lower energy intake than men. Mean diet scores, measured by $24 \mathrm{hR}$, were 4.9 (SD 1.0) for DHD15-index and 500 (SD72) for NRD9.3; with the diets of women having a higher dietary quality (respectively 5.3 vs 4.6 , and 507 vs 493). Measured by two replicates of the $24 \mathrm{hR}$, mean (SD) estimated crude environmental impact of the diet was 3.6 (SD 1.5) kg CO2e/d for GHGE, 31.1 (SD 9.2) MJ/d for FE, and 4.2 (SD 1.8) $\mathrm{m}^{2 *}$ year/d for LU; summarised in a pReCiPe of 0.43 (SD $0.16)$, with the diets of women having a lower environmental impact (pReCiPe of 0.39 versus 0.46 ).

Meat, dairy, and beverage consumption contributed the most to the environmental impact, irrespective of the method of dietary assessment (meat 29\% of total daily dietary pReCiPe, dairy $16 \%$ and beverages $15 \%$ according to $24 \mathrm{hR}$, and with similar values for the FFQ) (Table 2). Impacts of type of meat, however, differed by method of dietary assessment with for the FFQ a higher contribution to $\mathrm{pReCiPe}$ and its components from non-processed meat and a lower contribution from processed meat (18\% vs $9 \%$ ) as compared to the $24 \mathrm{hR}$ ( $15 \%$ vs $14 \%$ ); consistent with reported intake differences. In addition, reported intakes of dairy and plant-based foods, like potatoes, bread, vegetables, legumes and fruit, were in general higher for the FFQ than for the 24hR. Contribution of the different food groups to daily diet-related environmental impact was dependent on the environmental impact measures for some food groups; meat had a higher share in total daily dietary GHGE and LU than in FE, while the opposite was seen for plant-based foods, fish and beverages.

Table 3 shows the diet-related environmental impact according to the FFQ and the $24 \mathrm{hR}$ as well as the ICC for the latter. Observed values for FFQ and $24 \mathrm{hR}$ were similar for protein, and environmental indicators $(<5 \%$ difference), but energy intake was overestimated by the FFQ (6\%). After energy-adjustment, we observed underestimated values for protein intake (6\%) and for diet-related environmental impact measures $(7-10 \%)$ by the FFQ. ICC for replicates of the $24 \mathrm{hR}$ were low ( $\leq$ 0.30 ) for all variables under study; they were slightly lower for observed residuals $(0.12-0.22)$ than for observed values $(0.17-0.28)$ and density residuals $(0.19-$ 0.30 ). Thus, most of the observed variation was due to within-person variation, such as day-to-day variability, rather than between-person variation.

The crude correlation coefficient between FFQ and $24 \mathrm{hR}$ was 0.46 for protein, and ranged from 0.35 for GHGE to 0.45 for FE, but weakened after covariate adjustment. When accounting for random error in the $24 \mathrm{hR}$, the correlation coefficient was 0.75 for protein, and ranged from 0.66 for GHGE to 0.76 for pReCiPe, as shown by the de-attenuated correlation coefficient. After adjustment for energy, de-attenuated correlation coefficients were similar when using observed residuals, but they were lower when using density residuals, except for protein.

Estimated attenuation coefficients, as displayed by the regression slopes $\lambda_{1}$, were all below one, pointing to a flattened slope phenomenon in associations when using the FFQ. This attenuation appeared to be more severe with the inclusion of the covariates age, gender and BMI in the measurement error model for all variables under study (attenuation coefficients were lower). Covariate-adjusted attenuation coefficient for observed values was 0.51 for protein, and ranged from 0.53 for GHGE to 0.57 for FE. Energy-adjustment by the residual method of observed values showed similar attenuation coefficients as with non-energy-adjusted values; and for density residuals, the fully-adjusted attenuation coefficients tended to be higher, i.e. attenuation was lower than for the non-energy adjusted values, but less marked for protein and GHGE (with attenuation coefficient of 0.54 for protein and from 0.57 for GHGE to 0.69 for FE).

In stratified analysis, patterns of results for group-mean bias, correlation coefficients, and attenuation coefficients were generally similar for men and women (Additional files 1 and 2). Estimated correlation coefficients and attenuation coefficients for observed values did not change with covariate adjustment; indicating that gender explained most of the variation in this population. However, when using energy-adjusted values, as compared to non-energy-adjusted values, attenuation coefficients appeared to be higher for density residuals, and this was more marked in women than in men.

Table 4 shows the association between dietary quality (DHD15-index and NRD9.3) and diet-related environmental impact using observed and de-attenuated $24 \mathrm{hR}$-values, and observed and calibrated FFQ-values, for different methods of energy adjustment. Regression coefficients represent the percentage change in diet score per unit increase in diet-related environmental impact. Diet-related environmental impact was significantly inversely associated with the food-based DHD15-index, for all environmental impact measures, and for all methods of dietary assessment. Compared to de-attenuated $24 \mathrm{hR}$-values, regression coefficients using FFQ-values as observed were weakened, and became closer when calibrated FFQ-values were used. For the nutrient-based NRD9.3, no statistically significant associations were observed for summary score pReCiPe and its component GHGE, but a positive significant association was observed for $\mathrm{FE}$ and a significant negative association for LU. Using de-attenuated $24 \mathrm{hR}$-values showed a negative association for LU, while using FFQ-values as observed showed a positive association and calibration could repair this. Considering the method of energy adjustment, for both DHD15-index and NRD9.3, associations based on 
Table 2 Contribution of the different food groups to daily intake and environmental impact in the NQplus Study, using FFQ and 24h recall

\begin{tabular}{|c|c|c|c|c|c|c|c|c|c|c|c|c|}
\hline \multirow[t]{2}{*}{ Food groups } & \multicolumn{6}{|c|}{ 24-h Recall } & \multicolumn{6}{|l|}{ FFQ } \\
\hline & $\mathrm{g} / \mathrm{d}(\%)$ & E\%d (\%) & GHGE (\%) & FE (\%) & LU (\%) & pReCiPe (\%) & $\mathrm{g} / \mathrm{d}(\%)$ & E\%d (\%) & GHGE (\%) & FE (\%) & LU (\%) & pReCiPe (\%) \\
\hline Potatoes & 2.5 & 4.1 & 1.7 & 3.0 & 2.1 & 2.1 & 3.3 & 3.9 & 2.0 & 3.5 & 2.5 & 2.5 \\
\hline \multicolumn{13}{|l|}{ Cereals, cereal products } \\
\hline Bread products & 5.2 & 18.1 & 3.7 & 5.5 & 4.4 & 4.3 & 5.5 & 15.2 & 3.4 & 5.1 & 4.3 & 4.1 \\
\hline Cake, Biscuits & 1.5 & 7.4 & 2.6 & 2.8 & 3.1 & 2.9 & 1.5 & 6.2 & 2.1 & 2.5 & 2.9 & 2.5 \\
\hline Pasta,rice,couscous & 2.0 & 5.4 & 1.8 & 1.8 & 2.9 & 2.3 & 3.0 & 5.5 & 2.7 & 2.2 & 3.7 & 3.1 \\
\hline Vegetables & 5.1 & 1.9 & 5.1 & 8.0 & 1.9 & 4.3 & 6.9 & 2.3 & 5.4 & 9.1 & 2.0 & 4.6 \\
\hline Legumes & 0.2 & 0.4 & 0.2 & 0.4 & 0.2 & 0.3 & 0.6 & 0.7 & 0.6 & 0.9 & 0.4 & 0.6 \\
\hline Fruit & 5.7 & 5.1 & 3.8 & 5.1 & 1.9 & 3.3 & 8.0 & 5.4 & 4.9 & 6.7 & 2.4 & 4.2 \\
\hline Nuts and seeds & 0.4 & 3.3 & 0.6 & 0.6 & 2.3 & 1.4 & 0.6 & 4.4 & 0.9 & 0.9 & 3.3 & 1.9 \\
\hline \multicolumn{13}{|l|}{ Dairy } \\
\hline Cheese & 1.2 & 5.8 & 8.7 & 4.7 & 5.6 & 6.6 & 1.3 & 4.8 & 8.4 & 4.5 & 5.3 & 6.4 \\
\hline Milk $^{\mathrm{a}}$ & 6.1 & 4.2 & 5.9 & 4.9 & 4.0 & 4.9 & 7.8 & 4.1 & 6.8 & 5.5 & 4.5 & 5.6 \\
\hline Milk-based desserts ${ }^{b}$ & 4.4 & 4.7 & 5.4 & 4.3 & 3.3 & 4.3 & 5.4 & 4.8 & 5.8 & 4.7 & 3.5 & 4.6 \\
\hline \multicolumn{13}{|l|}{ Meat } \\
\hline Non-processed ${ }^{c}$ & 1.4 & 3.1 & 15.7 & 9.4 & 16.9 & 15.0 & 1.6 & 2.8 & 18.6 & 9.8 & 20.5 & 17.8 \\
\hline Processed $^{d}$ & 1.7 & 5.5 & 14.9 & 8.8 & 14.3 & 13.6 & 1.4 & 3.7 & 9.5 & 6.2 & 8.8 & 8.6 \\
\hline Fish & 0.7 & 1.7 & 2.9 & 4.9 & 1.1 & 2.5 & 0.7 & 1.2 & 3.0 & 5.1 & 0.6 & 2.3 \\
\hline Eggs & 0.5 & 1.0 & 1.3 & 1.5 & 1.6 & 1.5 & 0.6 & 0.9 & 1.4 & 1.6 & 1.7 & 1.6 \\
\hline \multicolumn{13}{|l|}{ Vegetarian products } \\
\hline Soy drink, desserts ${ }^{\mathrm{e}}$ & 0.1 & 0.1 & 0.0 & 0.1 & 0.1 & 0.0 & 0.3 & 0.2 & 0.1 & 0.1 & 0.1 & 0.1 \\
\hline Meat replacers & 0.2 & 0.3 & 0.2 & 0.3 & 0.2 & 0.2 & 0.2 & 0.3 & 0.3 & 0.4 & 0.3 & 0.3 \\
\hline Fats, Oils, Sauces & 1.1 & 6.4 & 2.5 & 2.2 & 4.3 & 3.2 & 1.8 & 10.1 & 3.2 & 3.3 & 7.4 & 5.0 \\
\hline Sugar, Sweets ${ }^{f}$ & 0.9 & 5.6 & 1.1 & 1.7 & 1.3 & 1.3 & 1.8 & 7.5 & 3.4 & 2.6 & 3.5 & 3.3 \\
\hline Snacks & 0.5 & 2.7 & 1.5 & 1.7 & 1.8 & 1.7 & 1.3 & 5.7 & 2.9 & 3.4 & 4.4 & 3.6 \\
\hline Soup, Composite dishes & 4.0 & 4.4 & 7.8 & 7.3 & 12.3 & 9.6 & 2.7 & 3.3 & 3.1 & 1.8 & 3.7 & 3.3 \\
\hline \multicolumn{13}{|l|}{ Beverages } \\
\hline Non-alcoholic & 48.0 & 2.8 & 7.9 & 13.6 & 8.3 & 9.1 & 40.0 & 4.7 & 9.9 & 16.4 & 13.3 & 12.5 \\
\hline Alcoholic & 6.2 & 5.6 & 4.5 & 7.3 & 6.0 & 5.6 & 3.7 & 2.2 & 1.6 & 2.6 & 1.0 & 1.5 \\
\hline
\end{tabular}

DHD15, Dutch Healthy Diet Index 15; NRD7.3, Nutrient Rich Diet score 7.3; GHGE, greenhouse gas emissions; FE, fossil energy use; LU, land use; pReCiPe, a weighted summary score for GHGE, FE, and LU

${ }^{a}$ milk: milk, milk beverages (chocolate milk) and coffee milk ${ }^{b}$ milk-based desserts: all kind of yoghurts, creams, and milk-based puddings and dessert ${ }^{c}$ nonprocessed meat: beef, pork, and chicken ${ }^{d}$ processed meat: meat products as sandwich filling, ham, ready-to-eat minced meat, sausages, organ meat and miscellaneous types ${ }^{\text {e }}$ soy drinks, desserts: soy-based drinks, yoghurts, puddings and creams ${ }^{f}$ Sugar, sweets: sugar, candy, sweet and savoury sandwich filling like jams, honey, chocolate spread, peanut butter

de-attenuated $24 \mathrm{hR}$-values were stronger for observed residuals than for observed values with inclusion of energy in the multivariate model, but were weaker for density residuals.

\section{Discussion}

Group-mean differences between FFQ and the reference $24 \mathrm{hR}$ were small $(<5 \%)$ for absolute values of GHGE, FE, LU and pReCiPe. Covariate-adjusted de-attenuated correlation coefficients between FFQ and $24 \mathrm{hR}$ were around 0.70 , and attenuation coefficients were around 0.55 for observed values on diet-related environmental impact measures. When we studied the association between environmental impact and dietary quality, an inverse association was observed when dietary quality was assessed using a food-based score (DHD15-index), but inconsistent and weak associations were seen when using a nutrient-based score (NRD9.3).

To the best of our knowledge, this is the first calibration study on diet-related environmental impact measures comparing the environmental impact obtained from FFQ with that of the $24 \mathrm{hR}$. The latter was used as reference instrument since no truly gold standard exist. As a means for comparison, we calculated correlation 
Table 3 Diet-related environmental impact according to the food frequency questionnaire (FFQ) and two replicates of the 24-h recall (24hR, with intra-class correlation coefficient) and group level bias, with correlation between the methods (crude, adjusted, deattenuated) and attenuation coefficient (crude, adjusted) ${ }^{\mathrm{a}}$ for observed and energy-adjusted values standardised to a $2000 \mathrm{kcal}$ diet

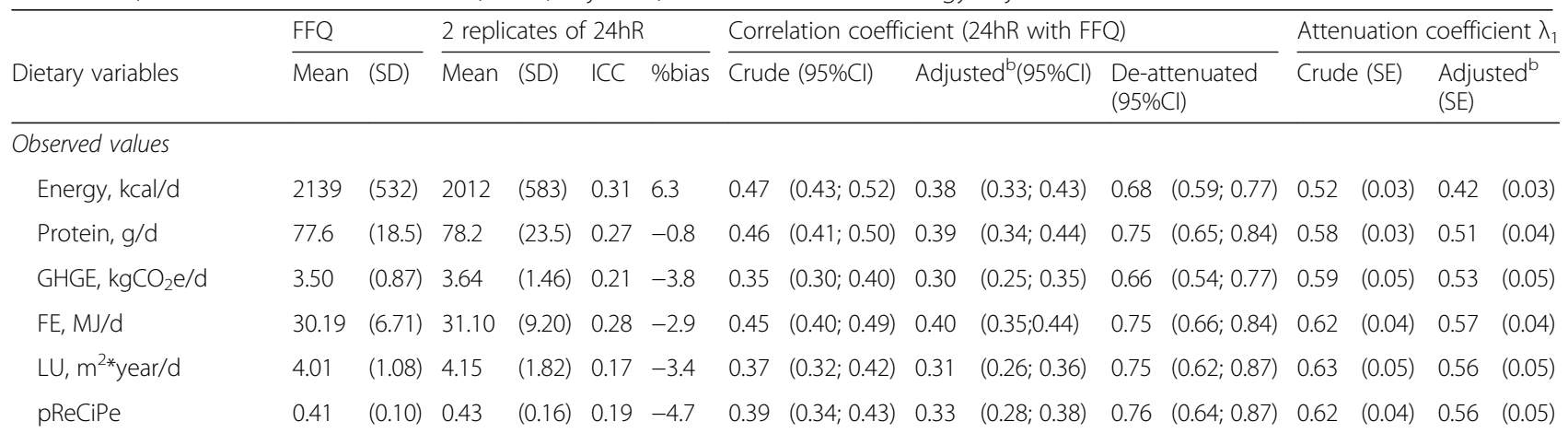

Energy-adjusted values by regression residuals of observed values on energy (observed residuals)

\begin{tabular}{|c|c|c|c|c|c|c|c|c|c|c|c|c|c|c|c|c|}
\hline otein, g/d & 3.5 & 0.3) & 77.9 & $(14.2)$ & 0.20 & -5.6 & 0.35 & $(0.30 ; 0.40)$ & 0.33 & $(0.28 ; 0.38)$ & 0.75 & $(0.63 ; 0.86)$ & 0.49 & (0.04) & 0.46 & $(0.04)$ \\
\hline $\mathrm{GHGE}, \mathrm{kgCO}_{2} \mathrm{e} / \mathrm{d}$ & 33 & $(0.61)$ & 3.63 & $(1.24)$ & 0.12 & -8.3 & 0.26 & 31) & 0.23 & 8) & 0.66 & 81) & 0.52 & $0.06)$ & .48 & (0.06) \\
\hline$=E, M J / d$ & 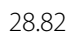 & $(4.21)$ & 30.98 & (6.77) & 0.22 & -7.0 & on & .43) & 0.35 & .40) & 0.10 & 86) & 0.62 & 0.04) & 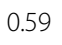 & \\
\hline$U, m^{2 *}$ year/d & 80 & $(0.71)$ & 4.14 & (1.56) & 0.13 & -8.2 & or & $.35)$ & 0.27 & $0.32)$ & 0.73 & D.88) & 0.65 & .06) & 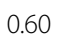 & \\
\hline ReCiPe, & 39 & $(0.07)$ & 0.43 & $(0.14)$ & 0.14 & -9.3 & 0.30 & $(0.24 ; 0.35)$ & 0.26 & $(0.21 ; 0.32)$ & 0.71 & $(0.57 ; 0.85)$ & 0.61 & .06) & 0.56 & \\
\hline
\end{tabular}

Energy-adjusted values by regression residuals of densities on energy (density residuals)

\begin{tabular}{|c|c|c|c|c|c|c|c|c|c|c|c|c|c|c|c|c|}
\hline$\%$ & 4.9 & 0) & 5.9 & 1) & 0 & 5.3 & 37 & & 35 & & 78 & & 7 & 1) & 4 & (1) \\
\hline$d$ & 3.38 & (10) & 3.73 & 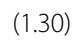 & 9 & -9.4 & 3 & 3) & 0.25 & 0) & 0.59 & 1) & 0.61 & $(0.06)$ & 57 & $(006)$ \\
\hline $\mathrm{J} / \mathrm{d}$ & 9.31 & $(4.09)$ & 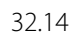 & (7.62) & 0.30 & -8.8 & .39 & 44) & (.) & & . & 74) & 0.73 & r & 0.69 & \\
\hline . & 83 & $(0.70)$ & 4.24 & (1.72) & 21 & . & & & & & & & 3 & ) & 77 & \\
\hline ReCiPe density & 0.40 & $0.06)$ & 0.44 & $0.15)$ & 22 & , & 031 & $(0.26 ; 0.36)$ & $0 . \angle 0$ & ;0.33) & & ; 0.71) & & $(0.06)$ & 55 & \\
\hline
\end{tabular}

ICC, intra class correlation coefficient; GHGE, greenhouse gas emissions; FE, fossil energy use; LU, land use; pReCiPe, a weighted summary score for GHGE, FE, and LU; \% bias, group-level bias calculated as (mean intake FFQ /mean intake $24 \mathrm{hR}) \times 100 ; 100$; correlation coefficient $(95 \% \mathrm{Cl}$ ) estimated as the Pearson correlation coefficient; de-attenuated correlation coefficient $(95 \% \mathrm{Cl})$ estimated as the Pearson correlation coefficient/ $\mathrm{JICC}_{24 \mathrm{~h} R}$; Attenuation coefficient $\lambda_{1}$ (SE) estimated as the slope in the linear regression of the $24 \mathrm{hR}$ on the FFQ using linear mixed models to account for within-person day-to-day variability

${ }^{a}$ Mean values with their standard deviations, correlation coefficient with its $95 \%$ confidence intervals, attenuation coefficient with its standard error

${ }^{\mathrm{b}}$ Adjusted for age, gender and BMI

coefficients and attenuation factors for protein intake as this is a widely studied nutrient in dietary validation studies. Correlation coefficients and attenuation coefficients for intake of energy and protein are in line with earlier calibration studies [33,37]. In the present study, the unadjusted correlation coefficient for protein was 0.46 (men: 0.41; women: 0.38), and the unadjusted attenuation coefficient for protein intake was 0.58 (men; 0.54; women. 0.48). Pooled analysis of protein intake in eight European validation studies within the European Prospective Investigation into Cancer [37] reported correlation coefficients between FFQ and $24 \mathrm{hR}$ varying between 0.35 and 0.67 , and attenuation coefficients for the FFQ on $24 \mathrm{hR}$ between 0.26 and 0.63 . In the US, the Observing Protein and Energy Nutrition (OPEN) study [33] reported correlation coefficients of 0.31 for men and 0.33 for women and attenuation coefficients of 0.53 for men and 0.70 for women. Thus, as compared to protein, correlation coefficients between these two methods tended to be slightly lower for all diet-derived measures of environmental impact, whereas attenuation coefficients were slightly higher, especially for FE and LU. As there was a strong correlation between measure of environmental impact and protein intake (correlation coefficients between 0.6-0.9), results might to some extent be affected by protein-poor food sources that contributed to diet-related environmental impact with their intake and contribution highly varying by the method of dietary assessment.

Changes in dietary intake are generally based on iso-caloric exchanges of foods, hence the need to keep energy intake constant when comparing diets between groups. Previous studies on the measurement error structure of self-reported protein intake have noted that the attenuation is less severe when energy intake is taken into account by either regression of protein intake on energy intake (protein residuals) or by the density method (dividing energy from protein intake by energy) $[13,33]$. Our analysis shows that the same holds for diet-derived measures of environmental impact, with less 
Table 4 Regression coefficients (with 95\% confidence intervals) ${ }^{a}$ for dietary quality, measured by food-based DHD15 -index and nutrient-based NRD9.3, and diet-related environmental impact, measured by GHGE, FE, LU, and pReCiPe, using observed and deattenuated 24-h recall (24hR)-values, and observed and calibrated FFQ-values, for different methods of energy adjustment in the total population

\begin{tabular}{|c|c|c|c|c|c|c|c|c|c|c|c|c|}
\hline \multirow{3}{*}{$\begin{array}{l}\text { Response variables } \\
\text { Explanatory variables }\end{array}$} & \multicolumn{6}{|c|}{ DHD15-index (based on 2 replicates of 24hR) } & \multicolumn{6}{|c|}{ NRD9.3 (based on 2 replicates of $24 \mathrm{hR}$ ) } \\
\hline & \multicolumn{2}{|c|}{ Observed values } & \multicolumn{2}{|c|}{ Observed residuals } & \multicolumn{2}{|c|}{ Density residuals } & \multicolumn{2}{|c|}{ Observed values } & \multicolumn{2}{|c|}{ Observed residuals } & \multicolumn{2}{|c|}{ Density residuals } \\
\hline & $\bar{\beta}$ & $(95 \% \mathrm{Cl})$ & $\bar{\beta}$ & $(95 \% \mathrm{Cl})$ & $\bar{\beta}$ & $(95 \% \mathrm{Cl})$ & $\beta$ & $(95 \% \mathrm{Cl})$ & $\beta$ & $(95 \% \mathrm{Cl})$ & $\beta$ & $(95 \% \mathrm{Cl})$ \\
\hline \multicolumn{13}{|l|}{ GHGE, per $1 \mathrm{kgCO} 2 \mathrm{e} / \mathrm{d}$} \\
\hline $24 \mathrm{hR}$ as observed & -3.3 & $(-4.1 ;-2.4)$ & -3.3 & $(-4.1 ;-2.4)$ & -2.7 & $(-3.5 ;-1.8)$ & -0.2 & $(-0.9 ; 0.6)$ & -0.2 & $(-0.9 ; 0.6)$ & -0.4 & $(-1.1 ; 0.3)$ \\
\hline De-attenuated $24 \mathrm{hR}$ & -11.3 & $(-14.1 ;-8.4)$ & -14.5 & $(-18.0 ;-10.9)$ & -8.3 & $(-10.8 ;-5.8)$ & -0.5 & $(-3.1 ; 2.0)$ & -0.7 & $(-4.0 ; 2.7)$ & -1.2 & $(-3.3 ; 1.0)$ \\
\hline FFQ as observed & -3.9 & $(-5.7 ;-2.0)$ & -3.9 & $(-5.7 ;-2.0)$ & -3.9 & $(-5.8 ;-2.0)$ & 1.0 & $(-0.5 ; 2.5)$ & 1.0 & $(-0.5 ; 2.5)$ & 1.1 & $(-0.5 ; 2.6)$ \\
\hline Calibrated FFQ & -8.3 & $(-10.8 ;-5.8)$ & -10.8 & $(-13.6 ;-8.0)$ & -7.7 & $(-9.8 ;-5.5)$ & 0.9 & $(-1.2 ; 3.2)$ & 0.8 & $(-1.7 ; 3.4)$ & -0.1 & $(-2.0 ; 1.8)$ \\
\hline \multicolumn{13}{|l|}{$\mathrm{FE}$, per $5 \mathrm{MJ} / \mathrm{d}$} \\
\hline $24 \mathrm{hR}$ as observed & -1.3 & $(-2.1 ;-0.5)$ & -1.3 & $(-2.1 ;-0.5)$ & -0.8 & $(-1.6 ;-0.1)$ & 1.3 & $(0.7 ; 2.0)$ & 1.3 & $(0.7 ; 2.0)$ & 0.7 & $(0.1 ; 1.3)$ \\
\hline De-attenuated $24 \mathrm{hR}$ & -2.9 & $(-4.8 ;-1.1)$ & -3.6 & $(-5.8 ;-1.3)$ & -1.8 & $(-3.4 ;-0.2)$ & 3.1 & $(1.5 ; 4.6)$ & 2.3 & $(1.9 ; 5.7)$ & 1.5 & $(0.2 ; 2.7)$ \\
\hline FFQ as observed & -1.7 & $(-3.1 ;-0.3)$ & -1.7 & $(-3.1 ;-0.3)$ & -1.6 & $(-3.0 ;-0.2)$ & 2.3 & $(1.2 ; 3.4)$ & 2.3 & $(1.2 ; 3.4)$ & 2.4 & $(1.2 ; 3.5)$ \\
\hline Calibrated FFQ & -2.5 & $(-4.3 ;-0.8)$ & -3.1 & $(-5.0 ;-1.3)$ & -1.9 & $(-3.3 ;-0.5)$ & 3.6 & $(2.1 ; 5.0)$ & 3.8 & $(2.3 ; 5.4)$ & 2.1 & $(0.9 ; 3.3)$ \\
\hline \multicolumn{13}{|l|}{$L U$, per $1 \mathrm{~m}^{2 *}$ year/d } \\
\hline $24 \mathrm{hR}$ as observed & -3.2 & $(-3.9 ;-2.5)$ & -3.2 & $(-3.9 ;-2.5)$ & -2.6 & $(-3.2 ;-2.0)$ & -0.6 & $(-1.2 ;-0.1)$ & -0.6 & $(-1.2 ;-0.1)$ & -0.9 & $(-1.4 ;-0.4)$ \\
\hline De-attenuated $24 \mathrm{hR}$ & -10.4 & $(-12.5 ;-8.3)$ & -13.2 & $(-15.8 ;-10.6)$ & -7.4 & $(-9.1 ;-5.6)$ & -2.1 & $(-4.0 ;-0.2)$ & -2.7 & $(-5.1 ;-0.3)$ & -2.6 & $(-4.1 ;-1.1)$ \\
\hline FFQ as observed & -6.3 & $(-7.8 ;-4.7)$ & -6.3 & $(-7.8 ;-4.7)$ & -6.2 & $(-7.7 ;-4.7)$ & 0.2 & $(-1.1 ; 1.5)$ & 0.2 & $(-1.1 ; 1.5)$ & 0.1 & $(-1.2 ; 1.4)$ \\
\hline Calibrated FFQ & -9.6 & $(-11.4 ;-7.7)$ & -11.4 & $(-13.3 ;-9.4)$ & -8.0 & $(-9.4 ;-6.4)$ & -0.8 & $(-2.4 ; 0.9)$ & -0.9 & $(-2.7 ; 0.9)$ & -1.7 & $(-3.0 ;-0.4)$ \\
\hline \multicolumn{13}{|l|}{ pReCiPe, per 0.1} \\
\hline $24 \mathrm{hR}$ as observed & -3.3 & $(-4.1 ;-2.5)$ & -3.3 & $(-4.1 ;-2.5)$ & -2.6 & $(-3.3 ;-1.9)$ & -0.3 & $(-0.9 ; 0.4)$ & -0.3 & $(-0.9 ; 0.4)$ & -0.6 & $(-1.2 ; 0.0)$ \\
\hline De-attenuated $24 \mathrm{hR}$ & -10.0 & $(-12.3 ;-7.7)$ & -12.9 & $(-15.7 ;-9.9)$ & -7.1 & $(-9.1 ;-5.2)$ & -0.8 & $(-2.9 ; 1.2)$ & -1.1 & $(-3.7 ; 1.6)$ & -1.6 & $(-3.3 ; 0.0)$ \\
\hline FFQ as observed & -5.1 & $(-6.8 ;-3.4)$ & -5.1 & $(-6.8 ;-3.4)$ & -5.1 & $(-10.3 ;-5.1)$ & 0.9 & $(-0.5 ; 2.3)$ & 0.9 & $(-0.5 ; 2.3)$ & 0.9 & $(-0.5 ; 2.4)$ \\
\hline Calibrated FFQ & -8.6 & $(-10.7 ;-6.5)$ & -10.6 & $(-12.8 ;-8.3)$ & -7.3 & $(-9.0 ;-5.5)$ & 0.5 & $(-1.3 ; 2.4)$ & 0.4 & $(-1.6 ; 2.5)$ & -0.6 & $(-2.1 ; 0.9)$ \\
\hline
\end{tabular}

DHD15-index, Dutch Healthy Diet Index 15; NRD9.3, Nutrient Rich Diet score 9.3; GHGE, greenhouse gas emissions; FE, fossil energy use; LU, land use; pReCiPe, a weighted summary score for GHGE, FE, and LU. De-attenuated 24hR-values estimated using the method of Best Linear Unbiased Prediction (BLUP) to correct for random error. Calibrated FFQ values calculated as the predicted values from a mixed model with FFQ-values, age, gender and BMI as covariates, accounting for random effects ${ }^{a}$ Regression coefficients represent the percentage change in diet score per unit increase in diet-related environmental impact, and are adjusted for energy intake (continuous and using estimates as measured by that method of dietary assessment), age (continuous), gender (men/women), and BMI (continuous)

attenuation for density residuals than for observed residuals. This is in line with the results of Table 4: regression coefficients using observed FFQ-values were closer to those using de-attenuated $24 \mathrm{hR}$-vales for densities residuals than for observed residuals. Measurement errors in the assessment of environmental impact are strongly correlated with errors in the measurement of total energy intake, and this appeared to be more marked for observed residuals, as shown by the lower ICC. This finding further supports the importance for using energy-adjusted intakes in nutritional epidemiology, however caution must be applied for their interpretation, as has been discussed previously [35]. Diet-related environmental impact is preferably expressed in relative values (i.e.: impact per $2000 \mathrm{kcal}$ ) rather than absolute values, because of the application of densities in public health recommendations. Individuals and populations can reduce their diet-related environmental impact per kcal consumed by replacing the intake of specific foods by environmental-friendly alternatives, thus by changing diet composition rather than total energy intake, unless physical activity and body weight have been changed substantially. Total energy intake is however strongly positively related to diet-related environmental impact as observed, which are absolute impact levels important in environmental sciences, hence the need for using density residuals.

In our study, the assessment of environmental sustainability of the diet was restricted by the availability of LCA data from 207 food products, resulting in an imprecise estimation of the environmental impact of the diet for both FFQ and 24hR. In addition, methods of dietary assessment to date have been developed to monitor food and nutrient intakes, without considering sustainable dietary practices, such as food origin, packaging and preparation methods, transport, storage, food waste, 
etc. Our results, however, show that the measurement errors for LCA-based environmental impact measures are of similar size as protein intake, which is at the better end of the range of errors in assessment of food and nutrient intake [33, 37, 38]. This was not hypothesized a priori. Nutrient-based selection of food items does not necessarily capture the variation for diet-related environmental impact measures, but apparently it does for the $24 \mathrm{hR}$ and FFQ in this study. This suggests that errors in classification (foods vs grouped items), portions size (specific vs standard) and frequency (FFQ only) largely explain the differences between the $24 \mathrm{hR}$ and FFQ, and eventually result in similar errors for estimated daily nutrient intake and environmental impact. Still, 24hRs (and diet records) provide more objective data on dietary practices, and for some food products packaging and preparation methods might by this time be recorded dependent on the dietary knowledge level and cooking skills of the subject. Provided that LCA data are more widely available for all kind of food products, these open-ended methods of dietary assessment that consider both healthy and environmental dietary practices would perform much better as compared to the FFQ, unless specifically designed for assessing environmental impact.

The secondary aim of this paper was to investigate the association between dietary quality (DHD15-index and NRD9.3) and environmental impact of the diet (24hR-based or FFQ-based). Dietary quality was used as independent variable using the $24 \mathrm{hR}$, and measures of environmental impact as dependent variable using both methods of dietary assessment (24hR and FFQ) without and with accounting for measurement error. Differences in regression coefficients can therefore be attributed to the ability of the $24 \mathrm{hR}$ versus FFQ to assess associations with environmental impact. Our results show that quality of the food pattern (DHD15-index in our case) is similarly related to all environmental impact measures under study, and more environmentally-friendly diets (lower value) tend to score better on food-based dietary quality (hence a negative regression coefficient); this is irrespective of the environmental impact measures. However, when nutrient quality of the diet (NRD9.3 in our case) is considered, the results differ by environmental impact measure and whether $24 \mathrm{hR}$ or FFQ was used as the method of dietary assessment.

In the detail for NRD9.3, we showed that nutrient quality tended to be positively associated with diet-related FE; but inversely with diet-related GHGE and LU. The reason for these apparently conflicting findings is likely attributable to the contribution of different food groups to daily diet-related environmental impact and nutrient intake. The positive association for diet-related FE with NRD9.3 is likely to be driven by food sources such as fish, bread, fruit and vegetables that have a higher contribution to total-diet related FE as compared to GHGE and LU (Table 2). Moreover, these foods have a high nutrient density contributing to high intakes of dietary fibre, potassium, magnesium, iron, vitamin $\mathrm{C}$, $\mathrm{E}$, and low intakes of sodium, added sugar and saturated fat. In contrast, the inverse association for $\mathrm{LU}$ is likely to be driven by the low contribution of fruit and vegetables to diet-related $\mathrm{LU}$ as compared to GHGE and FE (Table 2). This inverse association between LU and NRD9.3 was seen when using a 24hR, but not when using an FFQ; which might be explained by the higher intakes of fruit and vegetables observed in the FFQ. As the abovementioned foods played a less important role in the DHD15-index (only four out of fifteen components), an inverse association with diet-related environmental impact was found for this food-based diet score.

Our results are supported by previous studies that also showed inverse associations between diet-related GHGE and the food-based scores [11, 12, 39], whereas studies using nutrient-based scores showed no clear associations $[7,8,40]$. This discrepancy between results for food-based scores and nutrient-based scores may be explained by the different components included in the scores [41, 42]: food-based DHD15-index is conceptually related to food-based dietary guidelines and easily captures intakes of nutrient-dense plant-based foods versus animal-based foods; while the nutrient-based NRD9.3 evaluates dietary quality based on nutrient intake relative to nutritional requirements irrespective of the food sources. A sole focus on food-based approaches to a healthy and environmentally-friendly diet may therefore not capture the full spectrum of nutritional risks and may incorrectly lump all sustainability indicators together. Research is still needed to identify appropriate diet scores, differentially weighing various aspects of healthy and environmentally-friendly diets [43].

\section{Conclusion}

In conclusion, estimations of the environmental impact of the diet are dependent of the method of dietary assessment; the FFQ slightly underestimated environmental impact when compared with the $24 \mathrm{hR}$. Using energy-adjusted values resulted in a higher group mean bias and a lower correlation between FFQ and $24 \mathrm{hR}$, but there was less attenuation. Correlation coefficients and attenuation coefficients for environmental impact measures behaved in a similar way as for protein intake, this suggests that our findings and conclusions related to covariate- and energy-adjustment can be extended to other dietary factors. Moreover, de-attenuation of the $24 \mathrm{hR}$ and calibration of the FFQ to $24 \mathrm{hR}$ increases the strength of the associations between dietary quality and diet-related environmental impact. Higher dietary 
quality was associated with improved environmental impact for food-based scores, but no clear associations for nutrient-based scores. It is therefore important to include nutrient-based approaches, next to food-based approaches, to prevent that the transition to environmentally-friendly diets negatively affects nutritional status of the population.

\section{Additional files}

Additional file 1: Table S1. Diet-related environmental impact according to the food frequency questionnaire (FFQ) and two replicates of the 24 -h recall $(24 \mathrm{hR}$, with intra-class correlation coefficient) and group level bias, with correlation between the methods (crude, adjusted, deattenuated) and attenuation coefficient (crude, adjusted) for observed and energy-adjusted values standardised to a $2000 \mathrm{kcal}$ diet in men ${ }^{\text {a }}$. (DOCX $34 \mathrm{~kb}$ )

Additional file 2: Table S2. Diet-related environmental impact according to the food frequency questionnaire (FFQ) and two replicates of the 24-h recall (24hR, with intra-class correlation coefficient) and group level bias, with correlation between the methods (crude, adjusted, deattenuated) and attenuation coefficient (crude, adjusted) for observed and energy-adjusted values standardised to a $2000 \mathrm{kcal}$ diet in women ${ }^{\text {a. }}$ (DOCX $34 \mathrm{~kb}$ )

\section{Acknowledgements}

Not applicable.

\section{Funding}

Financial support for this original contribution was obtained from funding from the European Union's H2020 Programme under Grant Agreement number 633692 (SUSFANS: Metrics, models and foresight for European sustainable food and nutrition security), from TiFN under Project Agreement number 15SD01 (SHARP-BASIC), from ZonMw under Grant Agreement number 91110030 (Nutrition Questionnaires plus study).

\section{Availability of data and materials}

Not applicable.

\section{Authors' contributions}

PvtV, JMG and AK initiated the topic of the paper. EM, PvtV and HB were responsible for data analysis. EM, PvtV and AK were responsible for data interpretation. EM drafted the manuscript, which was reviewed by all authors for intellectual content. All authors read and approved the final version of the paper.

\section{Ethics approval and consent to participate}

The NQplus study was approved by the ethics committee of Wageningen University and conducted according to the Declaration of Helsinki, and all subjects provided their written informed consent.

\section{Consent for publication}

Not applicable.

\section{Competing interest}

The authors declare that they have no competing interest.

\section{Publisher's Note}

Springer Nature remains neutral with regard to jurisdictional claims in published maps and institutional affiliations.

\section{Author details}

'Division of Human Nutrition and Health, Wageningen University, PO Box 8129, 6700, EV, Wageningen, The Netherlands. ${ }^{2}$ TiFN, Wageningen, P.O. Box 557, 6700, AN, Wageningen, The Netherlands. ${ }^{3}$ National Institute for Public
Health and the Environment (RIVM), PO Box 1, 3720, BA, Bilthoven, The Netherlands.

Received: 1 August 2018 Accepted: 11 December 2018

Published online: 08 January 2019

\section{References}

1. Auestad N, Fulgoni VL 3rd. What current literature tells us about sustainable diets: emerging research linking dietary patterns, environmental sustainability, and Economics. Adv Nutr. 2015;6:19-36. https://doi.org/10. 3945/an.114.005694.

2. Hallström E, Carlsson-Kanyama A, Börjesson P. Environmental impact of dietary change: a systematic review. J Clean Prod. 2015;91:1-11. https://doi. org/10.1016/j.jclepro.2014.12.008.

3. Jones AD, Hoey L, Blesh J, Miller L, Green A, Shapiro LF. A systematic review of the measurement of sustainable diets. Adv Nutr. 2016;7:641-64. https:// doi.org/10.3945/an.115.011015.

4. Nemecek T, Jungbluth N, Canals LM, Schenck R. Environmental impacts of food consumption and nutrition: where are we and what is next? The International Journal of Life Cycle Assessment. 2016;21:607-20. https://doi. org/10.1007/s11367-016-1071-3.

5. Heller MC, Keoleian GA, Willett WC. Toward a life cycle-based, diet-level framework for food environmental impact and nutritional quality assessment: a critical review. Environ Sci Technol. 2013;47:12632-47. https:// doi.org/10.1021/es4025113.

6. Perignon M, Vieux F, Soler L-G, Masset G, Darmon N. Improving diet sustainability through evolution of food choices: review of epidemiological studies on the environmental impact of diets. Nutr Rev. 2017;75:2-17. https://doi.org/10.1093/nutrit/nuw043.

7. Clerfeuille E, Vieux F, Lluch A, Darmon N, Rolf-Pedersen N. Assessing the construct validity of five nutrient profiling systems using diet modeling with linear programming. Eur J Clin Nutr. 2013;67:1003-5. https://doi.org/10. 1038/ejcn.2013.95

8. Masset G, Vieux F, Verger EO, Soler LG, Touazi D, Darmon N. Reducing energy intake and energy density for a sustainable diet: a study based on self-selected diets in French adults. Am J Clin Nutr. 2014;99:1460-9. https:// doi.org/10.3945/ajen.113.077958.

9. van Dooren C, Marinussen M, Blonk H, Aiking H, Vellinga P Exploring dietary guidelines based on ecological and nutritional values: A comparison of six dietary patterns. Food Policy (2014) 44:36-46. doi https://doi.org/10.1016/j. foodpol.2013.11.002

10. Roos E, Karlsson H, Witthoft C, Sundberg C. Evaluating the sustainability of diets-combining environmental and nutritional aspects. Environ Sci Pol. 2015:47:157-66. https://doi.org/10.1016/j.envsci.2014.12.001.

11. Monsivais P, Scarborough P, Lloyd T, Mizdrak A, Luben R, Mulligan AA, Wareham NJ, Woodcock J. Greater accordance with the dietary approaches to stop hypertension dietary pattern is associated with lower diet-related greenhouse gas production but higher dietary costs in the United Kingdom. Am J Clin Nutr. 2015;102:138-45. https://doi.org/10.3945/ajcn.114.090639.

12. Biesbroek S, Verschuren WM, Boer JM, van de Kamp ME, van der Schouw YT, Geelen A, Looman M, Temme EH. Does a better adherence to dietary guidelines reduce mortality risk and environmental impact in the Dutch sub-cohort of the European prospective investigation into Cancer and nutrition? Br J Nutr. 2017;118:69-80.

13. Freedman LS, Schatzkin A, Midthune D, Kipnis V. Dealing with dietary measurement error in nutritional cohort studies. J Natl Cancer Inst. 2011; 103:1086-92.

14. Schatzkin A, Kipnis V, Carroll RJ, Midthune D, Subar AF, Bingham S, Schoeller DA, Troiano RP, Freedman LS. A comparison of a food frequency questionnaire with a 24-hour recall for use in an epidemiological cohort study: results from the biomarker-based observing protein and energy nutrition (OPEN) study. Int J Epidemiol. 2003;32:1054-62.

15. Kipnis V, Carroll RJ, Freedman LS, Li L. Implications of a new dietary measurement error model for estimation of relative risk: application to four calibration studies. Am J Epidemiol. 1999;150:642-51.

16. Rosner B, Spiegelman D, Willett W. Correction of logistic regression relative risk estimates and confidence intervals for random within-person measurement error. Am J Epidemiol. 1992;136:1400-13.

17. Kipnis V, Midthune D, Freedman LS, Bingham S, Schatzkin A, Subar A, Carroll RJ. Empirical evidence of correlated biases in dietary assessment instruments and its implications. Am J Epidemiol. 2001;153:394-403. 
18. van Lee $L$, Feskens EJ, Meijboom S, van Huysduynen EJH, van't Veer P, de Vries $\mathrm{JH}$, Geelen A. Evaluation of a screener to assess diet quality in the Netherlands. Br J Nutr. 2016;115:517-26.

19. Brouwer-Brolsma EM, van Lee L, Streppel MT, Sluik D, van de Wiel AM, de Vries $J H M$, Geelen A, Feskens EJM. Nutrition questionnaires plus (NQplus) study, a prospective study on dietary determinants and cardiometabolic health in Dutch adults. BMJ Open. 2018;8. https://doi.org/10.1136/bmjopen-2017-020228.

20. Moshfegh AJ, Rhodes DG, Baer DJ, Murayi T, Clemens JC, Rumpler WV, Paul DR, Sebastian RS, Kuczynski KJ, Ingwersen LA. The US Department of Agriculture Automated Multiple-Pass Method reduces bias in the collection of energy intakes. Am J Clin Nutr. 2008;88:324-32.

21. NEVO-tabel. Nederlands Voedingsstoffen-tabel (NEVO-tabel) 2011 (Dutch Food Composition Table 2011) Version 3. the Netherlands: RIVM/Dutch Nutrition Centre, Bilthoven; 2011.

22. Siebelink E, Geelen A, de Vries JH. Self-reported energy intake by FFQ compared with actual energy intake to maintain body weight in 516 adults. Br J Nutr. 2011;106:274-81.

23. Streppel MT, de Vries JH, Meijboom S, Beekman M, de Craen AJ, Slagboom PE, Feskens EJ. Relative validity of the food frequency questionnaire used to assess dietary intake in the Leiden longevity study. Nutr J. 2013;12:75.

24. Blonk H, Ponsioen T, Kool A, et al. The Agri-Footprint Method. Methodological LCA Framework, Assumptions and Applied Data. Gouda: Blonk Milieu Advies (ed); 2011.

25. Goedkoop M, Heijungs R, De Schryver A, Struijs J, van Zelm R. ReCiPe 2008. A LCA method which comprises harmonised category indicators at the midpoint and the endpoint level; Report 1 Characterisation; 2013.

26. Looman M, Feskens EJ, de Rijk M, Meijboom S, Biesbroek S, Temme EH, de Vries J, Geelen A. Development and evaluation of the Dutch healthy diet index 2015. Public Health Nutr. 2017;20:1-11.

27. Van Kernebeek HRJ, Oosting SJ, Feskens EJM, Gerber PJ, De Boer IJM. The effect of nutritional quality on comparing environmental impacts of human diets. J Clean Prod. 2014;73:88-99. https://doi.org/10.1016/j.jclepro.2013.11.028.

28. Drewnowski A. Defining nutrient density: development and validation of the nutrient rich foods index. J Am Coll Nutr. 2009;28:421S-6S.

29. Fulgoni VL 3rd, Keast DR, Drewnowski A. Development and validation of the nutrient-rich foods index: a tool to measure nutritional quality of foods. J Nutr. 2009;139:1549-54. https://doi.org/10.3945/jn.108.101360.

30. Wendel-Vos GC, Schuit AJ, Saris WH, Kromhout D. Reproducibility and relative validity of the short questionnaire to assess health-enhancing physical activity. J Clin Epidemiol. 2003;56:1163-9.

31. Freedman LS, Commins JM, Willett W, Tinker LF, Spiegelman D, Rhodes D, Potischman N, Neuhouser ML, Moshfegh AJ, Kipnis V. Evaluation of the 24hour recall as a reference instrument for calibrating other self-report instruments in nutritional cohort studies: evidence from the validation studies pooling project. Am J Epidemiol. 2017:1-10.

32. Park Y, Dodd KW, Kipnis V, Thompson FE, Potischman N, Schoeller DA, Baer DJ, Midthune D, Troiano RP, Bowles H, Subar AF. Comparison of self-reported dietary intakes from the automated self-administered 24-h recall, 4- $d$ food records, and food-frequency questionnaires against recovery biomarkers. Am J Clin Nutr. 2018;107:80-93. https://doi.org/10.1093/ajen/nqx002.

33. Kipnis V, Subar AF, Midthune D, Freedman LS, Ballard-Barbash R, Troiano RP, Bingham S, Schoeller DA, Schatzkin A, Carroll RJ. Structure of dietary measurement error: results of the OPEN biomarker study. Am J Epidemiol. 2003;158:14-21.

34. Donner A. A review of inference procedures for the Intraclass correlation coefficient in the one-way random effects model. International Statistical Review / Revue Internationale de Statistique. 1986;54:67-82. https://doi.org/10.2307/1403259.

35. Willett WC, Howe GR, Kushi LH. Adjustment for total energy intake in epidemiologic studies. Am J Clin Nutr. 1997;65:1220S-8S.

36. Singer JM, Stanek EJ, Lencina VB, González LM, Li W, San Martino S. Prediction with measurement errors in finite populations. Statistics \& probability letters. 2012;82:332-9.

37. Freedman LS, Commins JM, Moler JE, Arab L, Baer DJ, Kipnis V, Midthune D, Moshfegh AJ, Neuhouser ML, Prentice RL. Pooled results from 5 validation studies of dietary self-report instruments using recovery biomarkers for energy and protein intake. Am J Epidemiol. 2014;180:172-88.

38. Kynast-Wolf G, Becker N, Kroke A, Brandstetter BR, Wahrendorf J, Boeing H. Linear regression calibration: theoretical framework and empirical results in EPIC. Germany Annals of nutrition \& metabolism. 2002;46:2-8. https://doi. org/10.1159/000046746.
39. Murakami K, Livingstone MBE. Greenhouse gas emissions of selfselected diets in the UK and their association with diet quality: is energy under-reporting a problem? Nutr J. 2018;17(27). https://doi.org/ 10.1186/s12937-018-0338-x.

40. Walker C, Gibney ER, Hellweg S. Comparison of environmental impact and nutritional quality among a European sample population - findings from the Food4Me study. Sci Rep. 2018:8:2330. https://doi.org/10.1038/s41598-018-20391-4.

41. Kant AK. Indexes of overall diet quality: a review. J Am Diet Assoc. 1996;96: 785-91. https://doi.org/10.1016/s0002-8223(96)00217-9.

42. Arvaniti F, Panagiotakos DB. Healthy indexes in public health practice and research: a review. Crit Rev Food Sci Nutr. 2008;48:317-27. https://doi.org/10.1080/10408390701326268.

43. van Dooren $\mathrm{C}$, Douma $\mathrm{A}$, Aiking $\mathrm{H}$, Vellinga $\mathrm{P}$. Proposing a novel index reflecting both climate impact and nutritional impact of food products. Ecol Econ. 2017:131:389-98. https://doi.org/10.1016/j.ecolecon.2016.08.029.
Ready to submit your research? Choose BMC and benefit from:

- fast, convenient online submission

- thorough peer review by experienced researchers in your field

- rapid publication on acceptance

- support for research data, including large and complex data types

- gold Open Access which fosters wider collaboration and increased citations

- maximum visibility for your research: over $100 \mathrm{M}$ website views per year

At BMC, research is always in progress.

Learn more biomedcentral.com/submissions 